\title{
Severe mental illness and airports - the scope of the problem
}

\author{
AIMS AND METHOD \\ Mental illness may cause specific \\ problems in the environment of an \\ international airport. The aim of our \\ study was to assess frequency, \\ presentation and safety implications \\ of mental disorders requiring formal \\ admission at an international airport. \\ We performed a retrospective study \\ over 4 years including patients who \\ were detained by the police and \\ admitted.
}

\author{
RESULTS \\ The frequency of admissions was one \\ per million passengers, the \\ frequency of incidents raising safety \\ concerns was four per 10 million \\ passengers. An in-flight disturbance \\ occurred in 1.4 per 10 million arriving \\ passengers. Most common were \\ schizophrenia or schizotypal disorder \\ $(46.8 \%)$ and mania $(22.6 \%)$. Twenty \\ per cent of patients presented with \\ wandering.
}

\author{
CLINICAL IMPLICATIONS \\ Emergency admissions and incidents \\ causing safety concerns were rare. \\ Airport wandering was a frequent \\ presenting sign that should be \\ recognised.
}

Air travel is now widely available and used by large numbers of people. Heathrow Airport, for example, served more than 50 million passengers to about 200 destinations worldwide in 1998. There are only few studies addressing the psychiatric problems associated with air travel. Anxiety is common among air travellers (IIJon Foreman \& lljon, 1994; Mclntosh et al, 1998). Serious psychiatric disturbances have been observed (Miller \& Zarcone, 1968; Shapiro, 1976; Jauhar \& Weller, 1982; Lowe-Ponsford \& Begg, 1996) but the frequency of severe psychiatric disturbances at international airports is largely unknown. The aim of this study was to assess frequency, presentation and safety implications of profound psychiatric disturbances at Heathrow Airport.

\section{Method}

\section{Subject selection}

Adult patients (age $>16$ years) who were admitted from Heathrow Airport after being detained by Heathrow police between 1 March 1995 and 28 February 1999 were included. All patients appeared to be suffering from mental disorder and in immediate need of care and control to the police. They were taken to a place of safety under Section 136 of the Mental Health Act 1983 and admitted to Hillingdon Hospital after assessment by a psychiatrist and a social worker. Hillingdon Hospital served as the place of safety for Heathrow Airport; we were therefore in the position to obtain complete data on this patient population. We used an electronic database from the contracts and information department of the hospital and data regarding patients from Heathrow Airport from our bed manager (M.A.). For each patient we verified the admission from Heathrow Airport under Section 136 using the social worker's report. The identified names were cross-checked with a list of mental health assessments provided by social services. To minimise the chance that patients had been taken to another hospital (in violation of the policy) we contacted the doctors who are involved in Mental Health Act assessments, the bed managers of neighbouring hospitals, Heathrow police and social services.

\section{Data collection}

The following data were collected: name, gender, age, date of admission, date of discharge, ICD-10 diagnosis (World Health Organization, 1992), nationality, circumstance of admission, arrival from where, clinical presentation (psychotic, violent, aggressive, wandering, deliberate self-harm (actual or threatened), incident that happened in the air, disrupting air travel, self-neglect, repetitive presentation, other) and follow-up arrangements. Information on the clinical presentation and travel details was obtained from the approved social worker's report. This standardised report contained the following sub-headings: (a) reason for referral; (b) family and home situation; (c) social factors; (d) cultural factors; (e) details of interview; ( $f$ ) consultation with doctors; ( $g$ ) consultations with nearest relative/others; ( $h$ ) alternatives considered; and (i) risk assessment/conclusions.

\section{Classification of mental disorder}

At the time of discharge the patient's mental disorder was coded by the treating psychiatrist using the ICD-10 classification of mental and behavioural disorders (World Health Organization, 1992).

\section{Patients not included in this study}

This study does not include people with mental health problems who had been dealt with by other passenger services such as stewardesses, etc.; those not suffering from mental illness and who were arrested and charged for criminal offences; those who presented to the hospital voluntarily without police involvement and were 
admitted without formal Mental Health Act assessment ('informal admissions') and; persons who were initially

original papers detained by Heathrow police but where a mental health assessment revealed that contained detention was not justified.

\section{Results}

Two hundred and ninety people were brought to Hillingdon Hospital by Heathrow police, of whom 220 were admitted, 153 on Section 2 of the Mental Health Act. Data were incomplete in 30 patients, who were excluded, leaving 190 for further analysis. One patient was admitted twice.

\section{Demographic data}

The mean age was 36.8 years (s.d. 12.13). Eighty-one patients (43\%) were female, 109 (57\%) were male. One hundred and thirty-seven patients $(72 \%)$ were nationals in European states. Thirty-one patients (16\%) were nationals in states in North or South America. Thirteen patients (7\%) were nationals in states in India, South East Asia, the Pacific region or Australia. Nine patients (5\%) were from the Middle East or Africa.

Sixty-eight patients (one-third of all Section 136 admissions) were detained by the police after their arrival by plane. In the same period 98200000 passengers had arrived at Heathrow Airport (6.93 admission per 10 million arriving passengers). Patients were arriving from different regions; the admission rates from different regions were similar (admission rate 3.2 per 10 million arriving passengers from Africa and Middle East, 4.7 per 10 million from Asia, 7.3 per 10 million from America and 7.9 per 10 million from Europe).

One-hundred and twenty-two patients (two-thirds of all admissions) had entered Heathrow Airport from within the UK. In the same period 98030000 passengers had departed from Heathrow Airport (1.22 admission per 1 million departing passengers). Thus, the admission rate was about five times higher in patients arriving from within the UK than in patients arriving by plane. Taking patients arriving by plane and patients arriving from the UK together, there were 9.68 admission per 10 million passengers from Heathrow Airport.

\section{Clinical presentation}

Fig. 1 shows the clinical presentation. The most common presentations were psychotic or bizarre behaviour, aggression and wandering. Bizarre behaviour at the airport often caused security concerns. For example, sniffer dogs were used to recover a patient's clothes that he had buried in rabbit holes. Another patient caused security concerns because of refusal to board the plane after the luggage had been loaded on the plane. Violent behaviour was reported only in $14 \%$ of patients (1.3 in million passengers), threatening self-harm or inflicting minor self-harm (i.e. superficial cutting) occurred in $11 \%$ or 1 in 10 million passengers. Wandering was the third most frequent clinical presentation. Twenty per cent of patients presented as 'wandering'. Of all wandering patients $50 \%$ had psychotic symptoms in addition to wandering, 20\% were aggressive and/or violent. Schizophrenia or schizotypal disorder were the most common diagnoses in wandering patients.

Fourteen of 68 arriving patients (21\%) had caused in-flight disturbances. Most common was aggressive behaviour (seven patients); one patient with mania tried to open the door during the flight. Less severe incidents include pouring water over a fellow traveller; screaming; and undressing in the toilet. Nine patients had schizophrenia or a schizotypal disorder, five patients had mania. There was no increase of incidents per year over the study period.

\section{Psychiatric diagnosis}

Fig. 2 shows the spectrum and frequency of mental illnesses in patients from Heathrow Airport.

\section{Follow-up arrangements}

The mean stay was 9.75 days (s.d. 14.4), median 6 days. The distribution of stay in the hospital was skewed (skew 4.08), with a high proportion staying less than a week (52\%). Eighty (42\%) patients were transferred to another psychiatric hospital in the UK or overseas for further

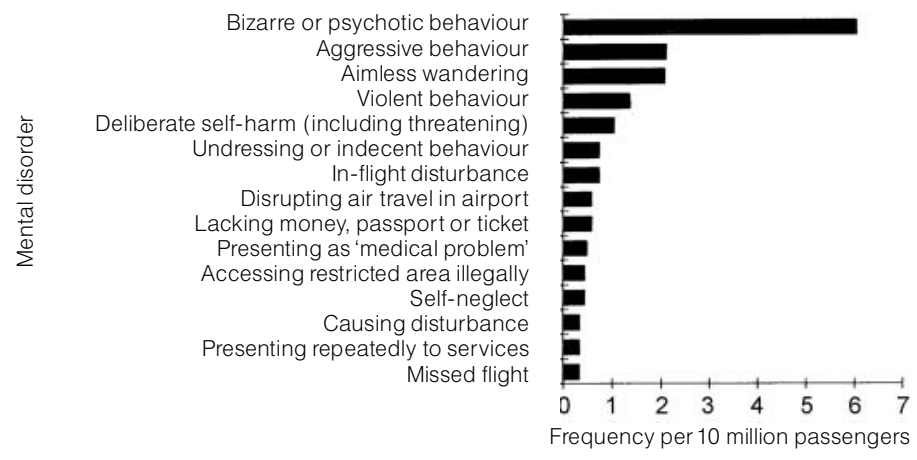

Fig. 1 Presentation of mental disorders at Heathrow Airport per 10 million passengers 
treatment. Fifty-five patients required repatriation to an overseas destination with an escort from the Hillingdon Hospital.

\section{Discussion}

Our data show that compulsory psychiatric emergency admissions from Heathrow Airport are, compared with the large number of air travellers, only rarely required. Only about one person in 1 million passengers required emergency psychiatric admission after detention by the police. The majority of patients presented with bizarre and at times disruptive, but not dangerous, behaviour. Wandering was a frequent and important symptom of mental illness at Heathrow Airport. This finding is in agreement with Shapiro (1982).

Our study demonstrated that patients admitted under Section 136 from Heathrow Airport frequently had severe mental illness. This result is very similar to the result of a study performed approximately 18 years ago at the same airport. In that study $50 \%$ of admitted patients had schizophrenia and 29\% had affective disorder (Jauhar \& Weller, 1982). In a study on patients from Kennedy Airport in New York, 74\% had schizophrenia and 5\% had an affective disorder (Shapiro, 1976). The differences between the UK and American studies may be owing to differences in the diagnostic classification (Gurland et al, 1970). Nevertheless, both studies agreed with our study admitted patients from international airports frequently have severe mental illness. This finding is not merely a reflection of the subject selection; in an inner-London area (Spence, 1995) the same selection criteria as our study were applied (detention by the police under Mental Health Act involving the same police force) but personality disorder was the primary diagnosis in about $30 \%$ of patients - far more than in our study. The different findings may reflect a different pattern of behaviour of patients with psychosis and personality disorder, the former having the tendency to travel (Ødegaard, 1932).

Patients only rarely caused in-flight disturbances. The frequency of in-flight disturbances caused by patients with mental illness in our study was much smaller than the reported frequency of physical medical emergencies in-flight; 1.4 psychiatric in-flight incidents per 10 million arriving passengers, as opposed to three in-flight medical emergencies per 100000 arriving passengers (Cummins \& Schubach, 1989; Speizer et al, 1989).

The frequency of all serious events caused by patients with mental illness, such as violent behaviour, disrupting air travel, deliberate self-harm, threatening self-harm and accessing restricted areas illegally, taken together, was four per 10 million passengers. This is well below the frequency of physical medical disorders at international airports, which have been reported to be about four per 10000 passengers (Antunano \& Aquino, 1989).

In conclusion, emergency admissions from Heathrow Airport and disturbances at the airport or in-flight were overall rare compared with the large numbers of travellers. A high proportion of patients from the airport suffered from schizophrenia or schizotypal disorder and mania. Follow-up studies could address the question of whether migratory tendencies persisted and whether these patients form a diagnostic entity. Airport wandering was a non-specific, but frequent sign of serious mental illness, which should be recognised.

\section{Acknowledgements}

We would like to acknowledge Sandy Van Brummen, Hillingdon Social Services and Richard Wainwright, BAA Research.

\section{References}

ANTUNANO, M. J. \& AQUINO, A. A. (1989) Seven years' experience in medical care at Mexico City International Airport. Aviation Space and Environmental Medicine, 60, 580-585.

CUMMINS, R. O. \& SCHUBACH, J. A (1989) Frequency and types of medical emergencies among commercial air travellers. Journal of the American Medical Association, 261, 1295-1299.

GURLAND, B. J., FLEISS, J. L., COOPER J. E., et al (1970) Cross-national study of diagnosis of mental disorders: hospital diagnoses and hospital patients in New York and London.
Comprehensive Psychiatry, 11, 18-25.

ILJON FOREMAN, E. \& ILJON, Z. (1994) Highwaymen to hijackers: a survey of travel fears. Travel Medicine International, 12, 145-152.

JAUHAR, P. \& WELLER, M. P. (1982) Psychiatric morbidity and time zone changes: a study of patients from Heathrow airport. British Journal of Psychiatry, 140, 231-235.

LOWE-PONSFORD, F. L. \& BEGG, A. (1996) Place of safety and section 136 at Gatwick Airport. Medicine, Science and the Law, 36, 306-312.

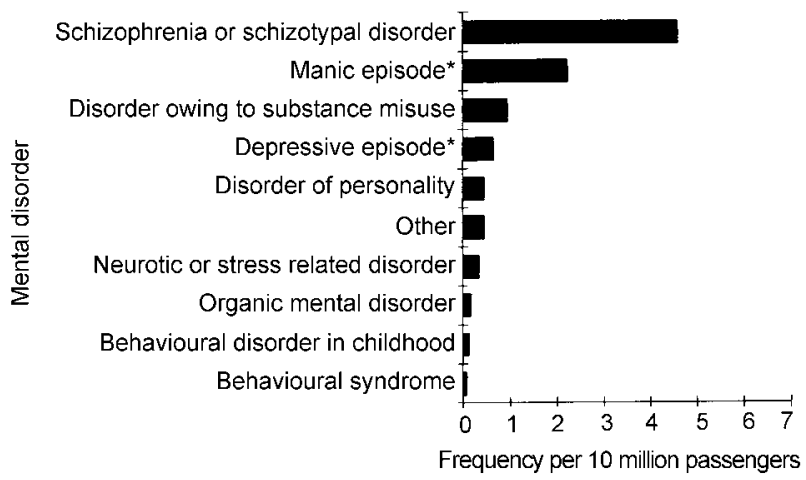

Fig. 2 Frequency of presentations of mental illness at Heathrow Airport per 10 million passengers * Single episode or in the context of a bipolar affective disorder. 
MCINTOSH, I. B., SWANSON, V., POWER, K. G., et al (1998) Anxiety and health problems related to air travel. Journal of Travel Medicine, $\mathbf{5}$,

original papers population of Minnesota. Acta

Psychiatrica/Neurologica

Scandinavica, Supplementum 4

SHAPIRO, S. (1976) A study of psychiatric syndromes manifested at an international airport. Comprehensive Psychiatry, 17, 453-456.

sychiatric behavior disorders at an international airport. Archives of Environmental Health, 17, 360-365.

ØDEGAARD, 0. (1932) Emigration and insanity. A study of mental disease among the Norwegian-born
— (1982) Airport wandering as a psychotic symptom. Psychiatria Clinica, 15, 173-176.
SPEIZER, C., RENNIE, C. J. \& BRETON, H. (1989) Prevalence of in-flight medical emergencies on commercial airlines. Annals of Emergency Medicine, 18, 26-29.

SPENCE, S. A. (1995) Personality disorder and police section 136 in Westminster: a retrospective analysis

*Udo Wieshmann PhD, TheWalton Centre for Neurology and Neurosurgery, Lower Lane, Fazakerley, Liverpool L9 7LJ M. Anjoyeb B. B. Lucas MRCPsych, The Hillingdon Hospital, Mental Health Unit, Pield Heath Road, Uxbridge, Middlesex UB5 3NN of 65 assessments over six month. Medicine, Science and the Law, 35 $48-52$

WORLD HEALTH ORGANIZATION (1992) The ICD-10 Classification of Mental and Behavioural Disorders. Geneva: WHO

\section{Developing a child and adolescent mental health service for children with learning disabilities}

\author{
AIMS AND METHOD \\ We discuss the development of a \\ service for children with learning \\ disabilities within a child and \\ adolescent mental health team using \\ the Health Advisory Service Together \\ We Stand tier system. The paper also \\ includes an audit of the service \\ 8 months after it was started.
}

\author{
RESULTS \\ We present a model of service that \\ has proved successful to date. We \\ give details from the audit of the \\ service, its aims, funding, referral \\ numbers, sources, types and criteria.
}

\begin{abstract}
CLINICAL IMPLICATIONS
The audit suggests that the aims of the service are being achieved but given the fact that the numbers of new referrals significantly outweigh the discharge rate, it is concluded that a greater emphasis is placed on liaison, consultation and joint working with other agencies.
\end{abstract}

In the past, mental health services for children with learning disabilities in York were separate from other child mental health services. They were provided in a patchwork way coordinated by the multi-disciplinary 'service for people with learning disabilities' and a clinical therapies directorate including psychology services. Over the years the services for children with learning disabilities evolved and were gradually eroded. The waiting-list reached 1 year and had to be closed. Many referrers became dissatisfied with the service and began to refer out of the district. In 1997 the provision of mental health services for children with learning disabilities was identified as an unmet need with respect to the Children's Charter (Department of Health, 1996). North Yorkshire health authority responded to concerns raised over the lack of services for these children by commissioning the Nuffield Institute for Health to undertake an assessment of need (Waddington \& Moore, 1998). Social services and education services were keen to develop cross agency services and were requesting a variety of mental health interventions.

In response to these circumstances York Child and Adolescent Mental Health Service (CAMHS) Directorate, based at Lime Trees, proposed the following: (a) a new integrated multi-disciplinary service with good multi-agency links

(b) that any new provision should recognise that ". . . the(se) children are among many with diverse special needs and should be provided for as children first and people with a particular disability second" (McKay \& Hall, 1994)

(c) that the management of the new childhood learning disability mental health service should be placed within the CAMHS Directorate in the York NHS Trust. This directorate includes multi-disciplinary services for children.

\section{Funding}

In June 1998 the CAMHS Directorate applied to North Yorkshire Health Authority for a fund of $£ 62000$ to develop a service for children with learning disabilities. In September 1998 the money was awarded from the Government's waiting-list initiative, and the CAMHS for learning disability was initially established on 1 January 1999, with all members of the team in place by April 1999. It should be noted that the posts of the community nurse and two sessions of clinical psychology time existed prior to the new funding and that the 